\title{
Supporting teachers' technological pedagogical content knowledge of fractions through co-designing a virtual manipulative
}

\author{
Alice Hansen $^{1} \cdot$ Manolis Mavrikis $^{1} \cdot$ Eirini Geraniou $^{1}$
}

Published online: 13 February 2016

(C) The Author(s) 2016. This article is published with open access at Springerlink.com

\begin{abstract}
This study explores the impact that co-designing a virtual manipulative, Fractions Lab, had on teachers' professional development. Tapping into an existing community of practice of mathematics specialist teachers, the study identifies how a cooperative enquiry approach utilising workshops and school-based visits challenged 23 competent primary school teachers' technological, pedagogical and content knowledge of fraction equivalence, addition and subtraction. Verbal and written data from the workshops alongside observations and interviews from the school visits were analysed using the technological, pedagogical and content knowledge (TPACK) framework. The findings show that the assumptions of even experienced teachers were challenged when Fractions Lab was shared as an artefact on which they were asked to co-design and subsequently interact with, using it in subsequent phases of the cooperative inquiry process. Two original aspects of successful co-design of virtual manipulatives through communities of practice are identified and offered to others: (1) careful bootstrapping of the first design iteration that gathers intelligence about the content area and the technological affordances and constraints available; and (2) involvement of highly motivated teachers who perceive themselves as agents of change in the domain area.
\end{abstract}

Keywords Cooperative inquiry · Co-design - Teacher professional development . Fractions · Mathematics education

Manolis Mavrikis

m.mavrikis@ucl.ac.uk; m.mavrikis@ioe.ac.uk

Alice Hansen

a.hansen@ucl.ac.uk

Eirini Geraniou

e.geraniou@ucl.ac.uk

1 London Knowledge Lab, UCL Institute of Education, 23-29 Emerald St, London WC1N 3QS, UK 


\section{Introduction}

The professional development (PD) landscape has undergone much change in the last three decades including establishing communities of practice (Jaworski 2001, 2003) and a shift from focusing on teaching per se to students' conceptual development (Borko 2004). Involving teachers in design processes has been a key strand throughout this time (Druin 1999; Heron and Reason 2001; Gravemeijer and van Eerde 2009; Scaife et al. 1997) and more recently an emerging focus has been on teachers adapting resources for their own use (Pepin et al. 2013) and the effect resources can have on teachers' PD (Remillard et al. 2008). Indeed, resources themselves can form the basis of a community of practice that transforms the resources as well as teachers' knowledge (Drijvers et al. 2013; Gueudet et al. 2013). In this article, we bring these three areas together. We report on how we tapped into an existing community of practice to engage specialist primary mathematics teachers as co-designers in a virtual manipulative, Fractions Lab, and the impact that had on their technological, pedagogical and content knowledge of fractions. The aim of this article, and its contribution, is to show how teachers' professional development can be enhanced through the co-designing of virtual resources in communities of practice.

The development of Fractions Lab was part of a larger study, iTalk2Learn, ${ }^{1}$ that developed an innovative online learning platform for elementary students to learn mathematics, and fractions in particular. Students undertake a range of structured and exploratory tasks using the platform, and Fractions Lab is the virtual manipulative intended to complement the structured tasks by supporting students' conceptual understanding.

In the following section, we review the professional development landscape and how the design of resources can be used in communities of practice to provide professional development opportunities. This follows with the research context, including an overview of how Fractions Lab supports students' conceptual understanding of fractions and provides the overall methodology of the wider project. Our research method including participants, data collection and analysis methods is next. In the following section, we present the data drawn from two parts of the study: (a) the teacher surveys, a selection of written and verbal comments during the workshop and (b) an analysis of the in-school work and reflections upon it from one of the teachers. We then discuss the results overall, focusing on the potential impact on teachers' technological pedagogical content knowledge. Finally, in the conclusion, we reflect on how the thorough initial design and the involvement of highly motivated teachers were key to the successful co-design of the virtual manipulative, Fractions Lab, through the community of practice in this study.

\section{Literature review}

Teacher professional development (PD) has significantly changed within recent history: in the 1950s, PD required teachers to be passive recipients of information imparted by experts, but by the 1980s-1990s there was a shift as calls for higher standards in teaching based on curriculum reform were commonplace (Wilson and Berne 1999; Cohen and Hill 2000), and there was a growing acknowledgement that curricular, pedagogical and assessment approaches to student learning could provide "powerful professional learning" for teachers within teachers' own contexts (Lieberman 1995). Furthermore, PD shifted to

${ }^{1}$ Talk, tutor, explore, learn: intelligent tutoring and exploration for robust learning. See www.iTalk2Learn. eu. 
encourage teachers to focus on children's conceptual development. As a result, "teachers reported an increased awareness of the role that children's thinking plays in the learning process, and the importance of listening clearly to students in order to build on their understandings and misconceptions" (Borko 2004).

In their research synthesis, Timperley et al. (2007) identified the features of what works in mathematics education PD. Interestingly, in relation to the context of professional learning opportunities, the amount of funding and time allocated, if teachers volunteered, and whether programmes involved whole schools, groups or individuals had little or no impact. Those aspects that were key to significant shift in practice were some form of collegial support alongside external expertise and clear goals that related to student achievement in mathematics. In relation to the content, Timperley et al. and Borko (2004) found that PD where teachers were engaged as learners in activities (such as solving mathematical problems), and they could see a positive impact for their pupils, was effective because teachers became more committed to the new approach.

The recent approach to supporting professional development within and beyond schools of the formation of supportive communities of practice (Jaworski 2001, 2003) reflects Timperley et al.'s findings. This approach has been called "an essential element in professional development programs" (Trigueros and Lozano 2012: 261). In addition, being a member of a group that shares and reflects upon technological pedagogical content knowledge can support teachers' confidence in integrating technology (Goos and Bennison 2008). Although communities of practice can take many forms, they have the shared understanding of the notion of co-learning and a community of practice where the members have a mutual enterprise, a shared commitment and a common repertoire (Pepin et al. 2013). For the purposes of this article, we adopt Pepin et al.'s (2013) interpretation of a common repertoire as a repertoire of resources, specifically the design of a virtual manipulative, Fractions Lab. One example of a community of practice in England is the Mathematics Specialist Teacher (MaST) programme (Williams 2008) that supports MaSTs to improve the standards of primary mathematics teaching and students' learning in their school or network of schools (Walker et al. 2013). In the USA, the eight-year MIST project is using researcher-practitioner relationships as co-designers of mathematics education policies and developing an empirically grounded theory of action for improving the quality of mathematics instruction at a large scale (Cobb et al. 2013).

\section{Co-designing as professional development}

Our motivation as educational researchers, teacher trainers and software designers is in identifying ways to engage teachers in design processes while making it a worthwhile process for them. This concern is shared with researchers from the field of technologyenhanced learning and human-computer interaction (HCI), where the traditional approach of involving users as a means of evaluating an application has been challenged and the value of involving people as participants or even co-designers in the design process is by now well understood (Bossen et al. 2010; Kafai 2003; Druin 1999; Scaife et al. 1997). Such an approach has the potential to help address the overarching concern in the field of education about the apparent estrangement of developers of digital educational resources from teachers and learners who are intended to use these resources (DfES 2003).

Our challenge therefore is to identify ways to effectively involve students and teachers in the design process. As such we have found congruence with the HCI approaches of "informant design" (Scaife et al. 1997), "cooperative inquiry" (CI) (Druin 1999; Heron and Reason 2001) and "classroom design-based research" (CDBR) (Gravemeijer and van 
Eerde 2009) that allows us on the one hand to involve more participants in the design process and on the other hand to aim for a mutual benefit for everyone involved. Both are important to us since not only we appreciate the value teachers bring with their involvement, we are also aware of the challenges they face due to their workload. We recognise, therefore, that PD opportunities might provide a fruitful avenue and advocate that one way of consolidating the PD, CI and CDBR needs is by orchestrating sessions that blend opportunities for providing informed feedback with opportunities for developing situated teacher expertise on technological, pedagogical and domain knowledge.

When appropriating resources for their own use, teachers adapt them for their own context. This process of "design" leads to the resource becoming "in-use" (Pepin et al. 2013). It is possible to involve a community of practice within the process of design-in-use involving users both during and after the process of designing a resource. Within this approach, the quality of a resource's fitness for purpose is identified "for a given context, for a given community, at a given stage of its development" (Pepin et al. 2013: 936). Further to appropriation, it is also possible to identify how resources shape a teacher's beliefs and practices (Remillard et al. 2008).

Technological resources are becoming more prolific and complex, and teachers, when integrating resources into their teaching, need to be involved in what Trouche (2004) refers to as instrumental orchestration. Drijvers et al. (2010) identify three elements within instrumental orchestration: (1) didactical configuration - the configuration of the teaching setting and the artefacts involved in it; (2) exploitation mode - the way the teacher decides to exploit a didactical configuration for the benefit of their didactical intentions; (3) didactical performance - the ad hoc decisions taken while teaching (responses on the fly) on how to actually perform in the chosen didactic configuration and exploitation mode.

Furthermore, resources can form the basis of a community of practice that transforms the resources themselves as well as the teachers' own learning (Drijvers et al. 2013; Gueudet et al. 2013). However, research exploring the collaborative design of resources and its impact on professional development is rare and on virtual manipulatives is rare. In her commentary paper, Remillard (2013) highlights the possibilities for instructional design and teacher collaboration that virtual resources offer over material resources because they have unique affordances and constraints that enable particular kinds of teacher and student interaction. She identifies how the design features of resources are important because they are "influential in their use and the instructional designs they promote is an area where more research is needed" (p. 549) - this article adds to this emerging body of research by identifying key two aspects for successful PD through the co-design of virtual resources in communities of practice.

\section{Teaching and learning fractions}

Fractions are an important aspect of the primary curriculum because children's performance in this area of mathematics predicts their mathematics achievement in high school, above and beyond the contributions of whole number arithmetic knowledge, verbal and non-verbal IQ, working memory, and family education and income (Siegler et al. 2012). Specifically, elementary fraction knowledge underpins the development of proportional reasoning, algebra and probability (Clarke and Roche 2009). However, it is widely accepted that fraction is one of the most difficult aspects of mathematics to teach and learn (Lamon 2012). One reason for this is the number of ways fractions can be represented: as 
spoken, graphical, symbols and actions (Cooper et al. 2012). The three most commonly cited graphical representations are area/region, number line and sets of objects (Duval 2006), and another is liquid measures (Silver 1983). England's National Numeracy Strategy (DfEE 1999) and subsequent Primary National Strategy (DfES 2006) encouraged teachers to use a range of representations including area/region representations beyond circles, sets of objects and number lines. Liquid measures are less commonly used.

Although the representations add complexity, using a range of representations is necessary for developing children's fractions understanding because each provide links to the underlying fractions concepts (Kong 2008) and children require support to make active connections within and between the various representations (Charalambous et al. 2010).

Teachers have at their disposal a wide range of representations, yet it is well documented that they tend to use a limited number, typically area models (Baturo 2004). The area representation is the most common in textbooks and other instructional materials around the world (Alajmi 2012; Pantziara and Philippou 2012). It often uses a figure such as a circle or rectangle with a fractional part shaded, resulting in a limited appreciation of fractions with respect to their possible interpretations. Furthermore, teachers tend to teach fractions procedurally rather than conceptually focusing on specific methods of doing operations with fractions, for example, and teaching students the steps involved in such methods without necessarily allowing students to appreciate the concept of a fraction (Chan et al. 2007; Cramer et al. 2002).

\section{Fractions Lab}

Fractions Lab (Fig. 1) is a virtual manipulative that was designed using a principled approach that exploited findings from a detailed literature review of fractions learning and teaching (Hansen et al. 2014; for an overview, see Sect. 3). It utilised a variety of fractions representations including continuous and discrete fractions and fractions in one, two and three dimensions (number line, area/region, and liquid measures, respectively).

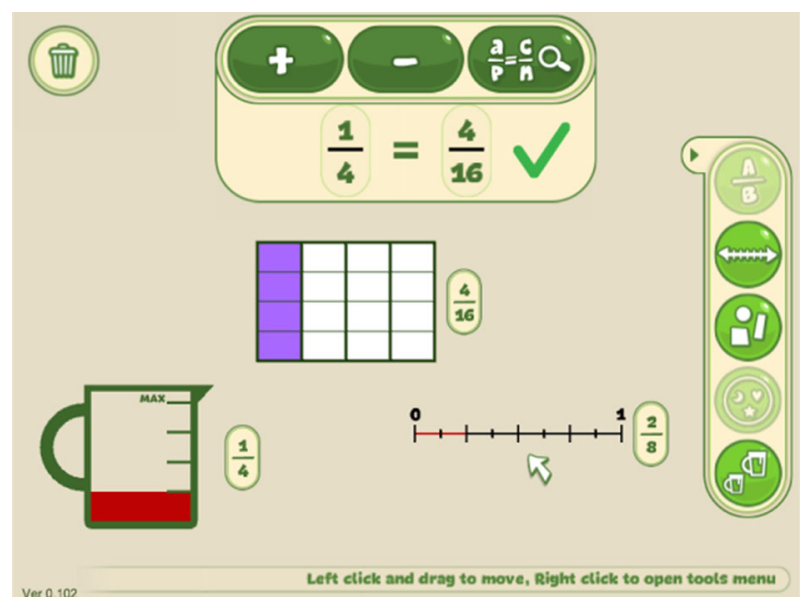

Fig. 1 Fractions Lab showing three representations and the "equivalence" tool at the stage of development this article reports upon 
Developing children's conceptual understanding with a virtual manipulative is not trivial; a number of affordances (tools) and constraints were designed for Fractions Lab to facilitate children's conceptual understanding. For example, these include: the "equivalence" tool (see "A" in Fig. 2) that provides feedback on whether the two fractions are equivalent; the "partition" tool that enables a child to split a representation and see the effect that has on the numerator and denominator (see "B" in Fig. 2); and the "join" tool that provides an animation showing two fractions added together. These actions can be performed on representations in a way that is difficult if not impossible away from the computer. For example, a student is able to establish a relation between a part and a whole by partitioning a rectangle and therefore changing the denominator and numerator while leaving the original whole intact, something that was often impossible without destroying the original (Olive and Lobato 2008) (see Fig. 2).

One example of a constraint in Fractions Lab relates to the addition of fractions: the sum is only provided if two fractions with like denominators are added together (see Fig. 3). This is designed to encourage children to create like denominators (using the partition tool) to carry out addition of fractions with uncommon denominators.

\section{Method}

The design, development and implementation of the iTalk2Learn learning platform used an iterative design research methodology (Cobb et al. 2003; Plomp and Nieveen 2009). Part of the iterative process informed the development of Fractions Lab that is embedded in the learning platform, by involving teachers as co-designers in the design process to ensure the design of a fit-for-purpose product, and thinking about how they would use Fractions Lab in the classroom.

Design-based research (DBR) is driven by the desire to innovate in education and to bring about educational improvement (Cobb et al. 2003). DBR is concerned with two strands - the iterative design/evaluation process to improve the product and concern for

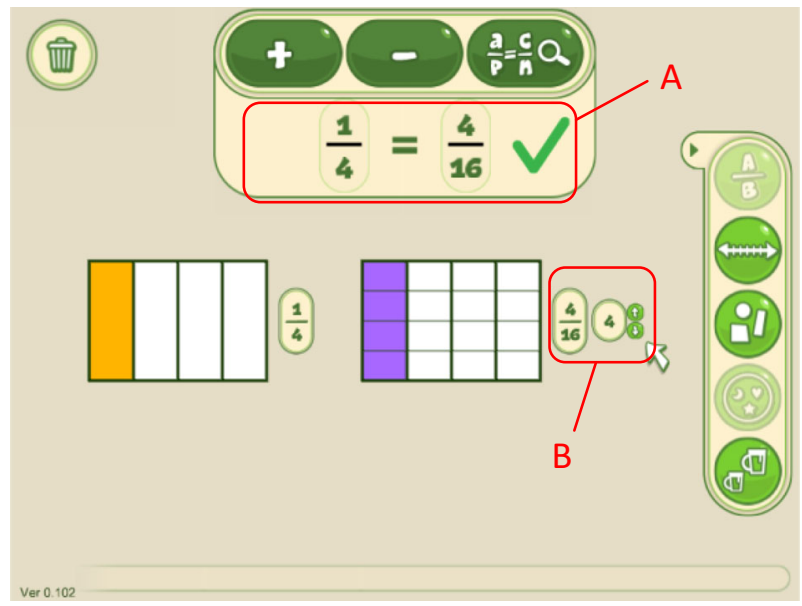

Fig. 2 Equivalence tool $(A)$ being used with area representations. The partition tool $(B)$ has split $1 / 4$ into four further sections to form $4 / 16$ 

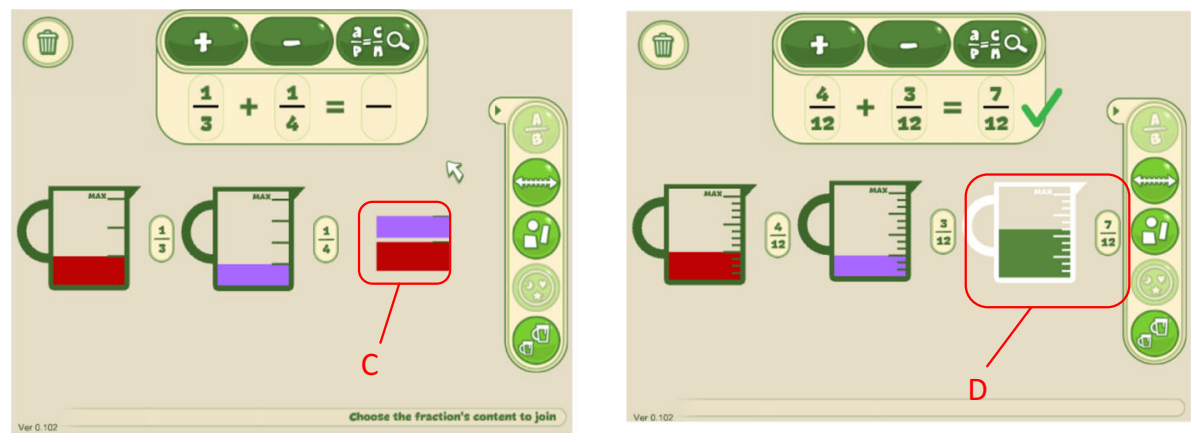

Fig. 3 Using the "join" tool with $1 / 3+1 / 4$ brings the fractional parts together but does not reveal the sum (C) compared to $4 / 12+3 / 12$ where the sum $7 / 12$ is shown $(D)$ as the fractions share a common denominator

learning about the students' learning trajectory. Through utilising a design-based methodology, it is possible to utilise design-trial-reflection cycles where a product (in this case the iTalk2Learn platform including Fractions Lab) enables researchers to learn about both how children learn and how to support that learning (Cobb et al. 2003). The first part of our DBR methodology was a bootstrapping task that involved co-design with mathematics education experts and 9- to 11-year-old students as informants (Druin 2002). This aspect proved critical within the teachers' PD and is briefly revisited in the conclusion, but this article focuses on the second part (iterative trialling cycles) where the research involved collaborative working with teachers to improve the initial design of Fractions Lab.

Although there are numerous studies emerging using design research with children in schools (Cobb et al. 2003; Reimann 2013), there are very few that focus on teachers' learning (Henrik et al. 2014; Pepin et al. 2013; Stephan 2014). While our primary objective is children's mathematical development, this study investigated the potential impact of designing Fractions Lab within the MaST community of practice to enhance the teachers' own technological pedagogical content knowledge. In order to do this, we adopted a cooperative inquiry approach (Heron 1996; Reason 1995) that researches with people (rather than on people) as co-researchers with similar concerns and interests. It is informative and transformative and has the potential for people to "address matters that are important to them" (Heron and Reason 2001: 180). We felt that a cooperative inquiry approach would support Timperley et al.'s (2007) finding that collegial support alongside external expertise and clear goals that related to student achievement in mathematics were effective methods of PD as well as encourage a process of design-in-action. This method involves four phases of reflection and action:

- Phase 1: A group of professionals meet to undertake inquiry about fractions teaching in primary schools.

- Phase 2: As co-researchers the process and outcomes of each other's actions are observed and recorded.

- Phase 3: As co-subjects we become fully immersed as we engage within our actions and experiences.

- Phase 4: We meet at an agreed time to consider our original ideas and develop them as appropriate. 


\section{Phases 1 and 2}

\section{Phases 1 and 2: participants and workshops method}

In Phases 1 and 2, we worked with four small cohorts of self-selected Mathematics Specialist Teachers (MaSTs) and teachers on an MA in Mathematics Education programme in two regions of England $(n=23)$. This teacher group was identified because they are participants of existing professional mathematics programmes in England designed to "impact on standards of mathematics teaching across the school" (Walker et al. 2013:13), and we envisaged that these expert primary mathematics teachers who are "active participants [and] viewed as professional contributors" (Penuel et al. 2007) would engage in co-designing Fractions Lab in a high-quality way. They were also an established group that had a shared understanding of the notion of co-learning and a community of practice where the members have a mutual enterprise, a shared commitment and a common repertoire (Pepin et al. 2013) related to the improvement of primary mathematics education. Their involvement was important to us because the extent to which innovations match teachers' goals for their own students' learning seems to influence their implementation (Fishman et al. 2006; Garet et al. 2001).

The teachers were invited to attend a voluntary 50-minute professional development workshop during a scheduled MaST day. The focus was to involve teachers as co-designers of Fractions Lab, improving its design and thinking about how they could use the Fractions Lab resource in their classroom and with colleagues. During the session the teachers were given the rationale for the design principles of Fractions Lab (including an overview of fraction representations and contemporaneous affordances/constraints) and then an opportunity to explore the first iteration of Fractions Lab, offer input on the design for the next iteration and consider how they might use it with their students and colleagues. The session concluded with a group discussion about Fractions Lab where we (a) took feedback on the design to feed into the next iteration (this is reported upon only briefly in this article) and (b) facilitated a group discussion about how the session had challenged teachers' own understanding of fractions, how the resource challenged their pedagogical approach to fractions and how teachers might use Fractions Lab in their teaching of fractions.

\section{Phases 1 and 2: data collection}

Data $^{2}$ were collected through recording the teachers' whole-group co-design discussions and making notes during small-group co-design discussions. The teachers completed a survey at the conclusion of the session, exploring the extent to which the Fractions Lab resource challenged the way that they think about and teach fractions. They were asked how likely they were to use Fractions Lab in their own teaching and recommend it to colleagues. They were asked to identify which fractions representations they were more likely to use in their teaching as a result of the session. Finally, they were asked to state whether they would like to participate further in the research, using Fractions Lab in school with us using a cooperative inquiry approach, entering Phase 3.

\footnotetext{
${ }^{2}$ We adhered to the BERA Ethical Guidelines for Educational Research (BERA 2011) and the university's ethical procedures. We gained permission from all participants (and their parents in the case of children). All participants (except Jonathan who has explicitly opted to be named) have been anonymised and cannot be identified.
} 


\section{Phases 1 and 2: data analysis}

Data in these phases were analysed using the technological pedagogical content knowledge (TPACK) framework (Mishra and Koehler 2006) as a means of considering the potential knowledge teachers develop that could help them integrate Fractions Lab (and technology in general) into their teaching practices. The lens of TPACK allows us to analyse the data and discuss teachers' comments and in these phases we categorise the teachers' verbal and written comments according to the three primary forms of knowledge: content, pedagogy and technology.

Content knowledge $(C K)$ : references to developing a concept of fractions, for example using and understanding fraction representations.

Pedagogical knowledge $(P K)$ : references to learning and teaching, such as thinking about how to help children learn more effectively.

Technological knowledge (TK): working with the affordances and constraints of Fractions Lab such as the partitioning tool or being able to only add two fractions when they share the same denominator.

While there are evident overlaps between the primary forms of knowledge, we intentionally consider these after the initial analysis in Phases 3 and 4, in order to explore the overlaps in the discussion.

While criticisms exist related to the clarity around TPACK's construct definitions and their relationship with each other (Cox and Graham 2009; Graham 2011; Voogt et al. 2013), in a similar vein to Drijvers et al. (2013: 989-990), "its elements seem appropriate to investigate the skills and knowledge teachers need to develop new orchestrations that fit to the available digital resources. Also, the model has the virtue of simplicity and accessibility". On occasion coding was not trivial (due to the relationships of the constructs). Where necessary, a second coder repeated the coding and discussion was had to gain a consensus.

\section{Phases 3 and 4}

Phase 3 involved working alongside the teachers in their classrooms. In Phase 4, weeks later, we revisited the teachers to consider earlier ideas and develop them as appropriate. In this article, we report upon our work with one of the teachers, Jonathan. We selected Jonathan because his case is typical of the teachers we worked with and presenting his work in school extends the findings from the workshops and allows a deeper analysis using the full TPACK framework.

\section{Phases 3 and 4: participants and engagement method}

We began working with Jonathan as co-researchers in his class of 9- to 10-year-olds as they used the iTalk2Learn platform individually. Jonathan then offered to be observed using Fractions Lab with one specific group of four students. Jonathan chose this group because he wanted to further his own understanding of the students' fractions attainment and use the resource to progress their fraction addition knowledge. They were a mixedattainment group comprising three boys and one girl. 


\section{Phases 3 and 4: data collection}

We videoed Jonathan's Phase 3 session and conducted an open-ended interview immediately afterwards. The purpose of this was to identify how Jonathan used Fractions Lab on the fly (Drijvers et al. 2013), how he felt it impacted upon his students' fractions understanding and how he envisaged using Fractions Lab in further lessons. We returned to Jonathan's school 6 weeks later to reflect with him upon his further use of Fractions Lab in class within Phase 4 of the study. We recorded his reflections.

\section{Phases 3 and 4: data analysis}

We once again used the TPACK framework as it emphasises the complex interplay of three primary forms of knowledge (content, pedagogy and technology) and the transformative nature of their intersection that results in four more knowledge bases applicable to teaching with technology. Because the data were collected from a realistic classroom situation, we found we could provide a more detailed analysis of Jonathan's interviews using the overlaps between the three primary forms in the TPACK framework:

Pedagogical content knowledge (PCK): covering key aspects of teaching and learning, PCK includes the transformation of fractions content for teaching, tailoring it to the students' needs.

Technological content knowledge (TCK): understanding how technology and fractions content can influence and constraint each other.

Technological pedagogical knowledge (TPK): understanding how technology can change teaching and learning.

The overall intersection (technological pedagogical content knowledge) characterises the knowledge (or the orientation as discussed by Bowers and Stephens 2011) required by teachers for technology integration in their teaching around a specific subject matter that "is the basis of effective teaching with technology, requiring an understanding of the representation of concepts using technologies [...] and how technology can help redress some of the problems that students face [...] and knowledge of how technologies can be used to build on existing knowledge to develop new epistemologies or strengthen old ones" (Koehler and Mishra 2009).

\section{Findings and analysis}

\section{Phases 1 and 2}

This section presents the data drawn from both the teacher surveys and the teachers' written $[\mathrm{W}]$ and verbal [V] comments. These data provide an insight into the impact that Iteration 1 of Fractions Lab and the short workshop had on the teachers' technological, pedagogical or content knowledge. The tables below show the responses in the teachers' surveys.

To what extent did Fractions Lab challenge the teachers' own thinking of fractions?

\begin{tabular}{lllll}
\hline None & Some extent & Great extent & Really challenged & Nil response \\
\hline 1 & 18 & 1 & 1 & 2 \\
$4 \%$ & $78 \%$ & $4 \%$ & $4 \%$ & $9 \%$ \\
\hline
\end{tabular}


Twenty out of the 23 teachers stated on the survey that designing and using Fractions Lab challenged their own thinking of fractions to at least some extent. In terms of content knowledge, the teachers reported thinking about the representations of fractions in more detail than they had previously, e.g. "I thought about the way that different representations need to be used more frequently than I use them now [W]". The workshop also challenged teachers' pedagogical knowledge to consider how they and their colleagues approach the topic of fractions with their pupils, e.g. "It has made me think about how we teach fractions as a whole staff [W]". Technological knowledge was also extended, e.g. "I'd never thought about splitting a rectangle up like that, you know, partitioning it so that you can see equivalent fractions so clearly. I've never made the connection myself before [V]".

To what extent did Fractions Lab challenge teachers' teaching of fractions?

\begin{tabular}{lllll}
\hline None & Some extent & Great extent & Really challenged & Nil response \\
\hline 3 & 15 & 3 & 2 & 0 \\
$13 \%$ & $65 \%$ & $13 \%$ & $9 \%$ & $0 \%$ \\
\hline
\end{tabular}

Twenty out of the 23 teachers stated on the survey that they felt Fractions Lab challenged their own fractions teaching to at least some extent. There were a number of content knowledge comments related to how teachers use representations, e.g. "I like the measures, I don't think I've used liquid measures with children before. It is a different way of exploring fractions with them [V]", and "Using the number line made me think about how little I do that with kids so it has made me think more about that as a representation and also the capacity representation which I think really gives them a clear idea [V]". There appeared to be a significant shift for two of the teachers in relation to pedagogical knowledge. Both of them were intrigued by the way Fractions Lab could be used by the children themselves to carry out tasks. One commented that she was really challenged by "More experimental learning for children for them to explore themselves rather than just being told [W]", while another stated, "The notion of children exploring themselves was interesting to challenging my pedagogy [W]". The three teachers who did not feel challenged explained that they had a sound pedagogical subject knowledge, e.g. one stated, "[My teaching of fractions has not been challenged because] I was taught fractions well; the MaST programme [W]". Another also explained her own level confidence but thought colleagues may benefit, e.g. "I'm comfortable teaching fractions but teachers lower down the school avoid teaching what they see as 'difficult' maths [W]". Technological knowledge was also represented in this question, as teachers reflected upon how the affordances of the technology supported mathematical concepts, e.g. "Fractions Lab challenged the way I teach fractions because of its ability to break up [the representations] into different equal parts, demonstrate adding etc. I usually do lots of drawing but this shows it more clearly [W]" and "To consider how methods such as adding fractions (where children would normally be expected to manipulate numbers) would be represented by pictures [W]".

To what extent did teachers state they were likely to use Fractions Lab in their teaching?

\begin{tabular}{llllll}
\hline Won't & Unlikely & Quite likely & Very likely & Definitely will & Nil response \\
\hline 0 & 0 & 12 & 8 & 3 & 0 \\
0 & 0 & $52 \%$ & $35 \%$ & $13 \%$ & $0 \%$ \\
\hline
\end{tabular}


All the teachers stated on the survey that they were at least "quite likely" to use Fractions Lab in their teaching. The reasons they gave for why varied. Content knowledge included a focus on a range of representations, e.g. "[I] liked the fact that you could show a $1 / 2$ in different ways, e.g. jug, number line etc [W]". One teacher considered pedagogical knowledge by considering the ways she could use Fractions Lab: "It is ideal for starters, guided groups or independent activity [W]". The way the technology could afford manipulation of the representations was identified in this question also, reflecting technological knowledge: "Good visual representations of the fractions. Like the partitioning aspect so you can change the fractions to share the denominator [W]", and "I don't know of another resource that would show equivalent fractions in the same way as Fractions Lab [V]".

To what extent did teachers state they were likely to recommend Fractions Lab to their colleagues?

\begin{tabular}{llllll}
\hline Won't & Unlikely & Quite likely & Very likely & Definitely will & Nil response \\
\hline 0 & 1 & 10 & 8 & 4 & 0 \\
$0 \%$ & $4 \%$ & $43 \%$ & $35 \%$ & $17 \%$ & $0 \%$ \\
\hline
\end{tabular}

Twenty out of 23 teachers stated that they were at least "quite likely" to recommend Fractions Lab to their colleagues. The one teacher who said they were unlikely explained their decision by stating, "[I am unlikely to recommend Fractions Lab to colleagues] while it is in this state. I may do when it is finished [W]". When justifying their selection, teachers who demonstrated content knowledge felt that the resource would "give other staff good visuals to use with their class to demonstrate fractions [W]" or provide "a simple way to introduce fractions to a colleague who is unsure [W]". Another stated, "The new curriculum has pushed fractions really up a lot with Year 6 now multiplying and dividing so teachers' subject knowledge is going to have to rise to that and this is definitely one way of ensuring that that happens or being part of that process. Definitely [V]". In relation to pedagogical knowledge, one teacher explained, "this needs to be rolled all the way through school so that children learn more through exploration and see different representations" [W] and another felt Fractions Lab is "suitable for all age groups" [W]. A further teacher demonstrated technological knowledge by considering that "it will form part of our approach to fractions [because] it provides a link between concrete and abstract [W]".

To what extent did Fractions Lab prompt teachers to adapt the representations they use?

\begin{tabular}{llllll}
\hline Area & Number line & Sets & Liquid measures & Symbols & $\begin{array}{l}\text { None, I'm happy with the } \\
\text { representations I'm using }\end{array}$ \\
\hline $6 / 23$ & $9 / 23$ & $6 / 23$ & $16 / 23$ & $3 / 23$ & $4 / 23$ \\
$26 \%$ & $39 \%$ & $26 \%$ & $70 \%$ & $13 \%$ & $17 \%$ \\
\hline
\end{tabular}

Only four teachers felt they did not need to adapt the representations they used. In all cases, these teachers taught Year 6 (10-11 year old) children and as one explained, "Being in Year 6, I use the past SAT [test] papers. They have all these representations so the children are familiar with them. But before they come up to me they are not. They've only seen area representations [V]". One teacher demonstrated their content knowledge by stating, "I liked the fact that you could show a $1 / 2$ in different ways e.g. jug, number line 
etc. It is suitable for all year groups [V]". Another teacher showed pedagogical knowledge by explaining, "It's nice that there's different representations like the capacity jug and number line. A lot of even the older children don't actually understand the value of a fraction and its place on a number line or can relate say 6/10ths of a litre. They just don't get that because they are too embedded with the numbers at that stage and it has gone away from the concrete manipulatives. It does that on the screen in a nice way [V]". Finally, demonstrating technological knowledge, a teacher wrote, "It gives ways to use the NCETM method for teaching addition of fractions in a very visual way! Good visual representations of the fractions. I like the partitioning aspect so you can change the fractions to share the same denominator [W]".

\section{Phases 3 and 4}

Nineteen out of the 23 teachers stated on the survey that were keen to be involved in Phase 3 of the study. Those who did not volunteer were not required to give a reason, but three of the four teachers did, stating "I'm moving age phase next year and want to focus on that", "I am moving schools" and "I'm finishing my MA and although I'd like to be involved I really need to concentrate on my dissertation".

Jonathan selected two children who were competent adding and subtracting fractions and two who had not been introduced to adding fractions beyond those with like denominators. One of these latter children, Dharma, is the focus of Jonathan's reflection. Jonathan asked the children, two working in a pair and two working independently, to carry out three tasks which he had planned on the fly during our session.

1. Add $3 / 7$ and $1 / 7$ (same denominators),

2. Add $3 / 7$ and $3 / 14$ (14 is a multiple of 7 ),

3. Add $3 / 7$ and $1 / 3$ (unlike denominators).

As we will see later in his reflections, Jonathan selected these questions taking into account the task difficulty alongside the affordances and constraints of Fractions Lab. He foresaw opportunities for interventions that would lead the children to make links between representations and procedures.

In Tables 1 and 2, we present excerpts from Jonathan's immediate reflection (Table 1), mainly focusing on one of the four children, Dharma, and his reflection 6 weeks later (Table 2), sharing his views on Fractions Lab, its value and impact on the teaching and learning of fractions.

We depict Jonathan's understanding visually in Fig. 4 that also shows the potential of using TPACK as an analytical and PD framework in that it allows us not only to identify key moments but also potentially to support the development of Jonathan's and in general a teacher's knowledge and help them reflect on how to integrate technology into their teaching.

\section{Discussion}

Despite being involved in a short workshop, all the teachers expressed interest in Fractions Lab, stating they were at least likely to use it in their own teaching, and 22 of the 23 teachers $(96 \%)$ reported they were at least quite likely to recommend it to colleagues. The teacher who did not feel she could recommend Fractions Lab qualified this by explaining that she might recommend it once she had seen Fractions Lab as a final product. This exemplifies Pepin et al.'s (2013) finding where the quality of a resource's fitness for 
Table 1 Jonathan's reflection and TPACK analysis

\begin{tabular}{|c|c|}
\hline Jonathan's reflection & Analysis (TPACK) \\
\hline $\begin{array}{l}\text { It was fabulous to see the children's understanding } \\
\text { and the representations there to guide them in their } \\
\text { thinking. The third one I made a little bit more } \\
\text { difficult because they had to partition not just one } \\
\text { of the structures but both of them. So we had } 3 / 7 \\
\text { and } 1 / 3 \text {. Again I worked with Dharma a little bit } \\
\text { and we looked at how ok, I can't convert 3rds into } \\
7 \text { th so can I convert that into } 21 \text { ths? And you could } \\
\text { see once she had got the idea of converting into } \\
21 \text { ths, she then took off and started partitioning } \\
\text { herself and very quickly worked it out and } \\
\text { understood it }\end{array}$ & $\begin{array}{l}\text { Dharma's use of representations observed (TPK) } \\
\text { Jonathan chooses a third, more challenging, task that } \\
\text { involves two fractions with unlike denominators } \\
\text { (PCK) } \\
\text { Jonathan's use of the constraint in Fractions Lab that } \\
\text { Dharma could not simply add any two fractions. } \\
\text { He encouraged Dharma to use partitioning to } \\
\text { support her addition of fractions with unlike } \\
\text { denominators (TCK) } \\
\text { Dharma's use of partitioning to model converting to } \\
\text { equivalent fractions following on from Jonathan's } \\
\text { intervention strategy, which focused on modelling } \\
\text { the first step in adding fractions of unlike } \\
\text { denominators and probing question? (TPK) }\end{array}$ \\
\hline $\begin{array}{l}\text { Without the tool, unless she was taught to find the } \\
\text { common denominator, she would not have been } \\
\text { able to do that activity, she wouldn't have been } \\
\text { able to work that out. And I think having that } \\
\text { visual representation, she is in the perfect place to } \\
\text { follow up to teach her about uncommon } \\
\text { denominators and how to find common } \\
\text { denominators }\end{array}$ & $\begin{array}{l}\text { Jonathan identifies how the design of Fractions Lab } \\
\text { was able to support Dharma's understanding of } \\
\text { addition because of its affordances and constraints } \\
\text { (TCK) } \\
\text { Jonathan reflects on how he would have taught } \\
\text { addition of fractions with unlike denominators } \\
\text { procedurally without Fractions Lab and supports } \\
\text { the potential value of using it (TPK) } \\
\text { Jonathan feels Dharma is in the position to } \\
\text { understand addition of fractions with unlike } \\
\text { denominators conceptually due to the visual } \\
\text { representations offered by Fractions Lab (PCK) }\end{array}$ \\
\hline $\begin{array}{l}\text { I think the visual representation allowed them to } \\
\text { freely understand why that was happening and } \\
\text { what was happening. And I think unless you have } \\
\text { got that, showing them converting common } \\
\text { denominators can be quite abstract and procedural } \\
\text { rather than really embedding understanding. I } \\
\text { think that was what is particularly valuable in this }\end{array}$ & $\begin{array}{l}\text { Jonathan reflects upon the affordances of the } \\
\text { representations and tools within Fractions Lab } \\
\text { (TCK) } \\
\text { Jonathan identifies how Fractions Lab can be used to } \\
\text { support children's conceptual understanding rather } \\
\text { than teaching them procedurally (TPACK) }\end{array}$ \\
\hline
\end{tabular}

purpose is considered in relation to the context and community at any particular stage of its development. Furthermore, 19 out of 23 teachers $(83 \%)$ wanted to be involved further in the project by being involved in Phase 3 . We find this level of engagement and commitment from a 50-min workshop positively reflects on the cooperative inquiry and iterative methodologies, and Fractions Lab's quality.

We were interested in how engagement in the design of Fractions Lab, a tool intended for children to learn fractions, could act as a tool in developing teachers' own technological pedagogical content knowledge. This resource brought together these teachers from an existing community of practice during the workshop that enabled them to become codesigners of Fractions Lab (Pepin et al. 2013).

\section{Teachers' pedagogical content knowledge}

The discussion and the written feedback were heavily dominated by fraction representations. Perhaps this is not surprising given that teachers' own approach is likely to employ predominantly, if not solely, area representations (Baturo 2004; Alajmi 2012; Pantziara 
Table 2 Jonathan's reflection 6 weeks later

\author{
Jonathan's reflection in response to the question, \\ Analysis (TPACK) \\ "How has Fractions Lab challenged either the way \\ you think about fractions or the way that you teach \\ fractions and why?"
}

\begin{abstract}
Definitely those representations of the number line and the capacity. The need for children to get a full understanding to see these different

representations. And I think, actually, being able to add fractions and cut and move things across. So I think it helps the teacher to extend our ideas and gives us some pedagogical ideas for teaching
\end{abstract}

The thing I particularly like about Fractions Lab is the partition function and they can see really clearly that when they are finding equivalent fractions that a half is the same as two quarters and so on. And even if they're not quite understanding how the digits are working within the fractions they're getting a visual representation that is really going to stick in their heads I think

Fractions Lab wouldn't allow me to do $3 / 7$ add $1 / 3$. You'd have to use a common denominator in that case. Actually being able to see what $3 / 7$ and a $1 / 3$ looked like it helped to kind of narrow down that shape and how full it would be. And then with the partitioning tool ... they have to make that leap. It was a magical moment when they did. They talked a lot about how it helped them. It was Dharma who struggled on this one. It was using Fractions Lab that really helped Dharma to be able to do this
Jonathan reflects upon the impact Fractions Lab has had on his pedagogical content knowledge of teaching fractions. It helped him reflect upon his current teaching approaches and provided him with useful ideas to implement in his future teaching of fractions

He recognises the value of interacting with the Fractions Lab's different visual representations for operating with fractions on students' conceptual understanding (PCK)

Jonathan emphasizes the value of one specific affordance of the Fractions Lab, that of the partition function (TCK)

Even though he recognises that students may revert to procedural understanding and not necessarily understand the method of finding equivalent fractions, he expects the visual representation to become part of students' memory, which could be retrieved when students come across equivalent fractions in the future (TCK)

Jonathan was able to see the impact of the constraint that Fractions Lab offers regarding adding fractions of unlike denominators, as it can lead to a more conceptual approach to manipulating fractions (TCK)

Jonathan talks about the 'magical moment' and how Fractions Lab supported students to make that 'leap' to conceptual understanding and consequently recognise the value of an exploratory learning environment on students' understanding (TPK)

Jonathan recognised the design idea of Fractions Lab for creating cognitive conflicts that challenge students' mathematical ways of thinking. Students' engagement and motivation to use Fractions Lab, but also their sense of achievement are evident in Jonathan's claim (TPK)

and Philippou 2012), and that Fractions Lab was designed specifically to address this issue. Many of the teachers reported feeling challenged to consider teaching using other representations. Indeed, 16 out of the $23(70 \%)$ teachers stated they were more likely to include liquid fractions in their teaching as a result of the workshop. The four teachers who did not feel challenged to use representations differently in their teaching are all Year 6 teachers (teaching 10- to 11-year-olds), and they explained they already use this range of representations. It appears that involving the teachers in the co-design of the resource at least whetted their appetite to consider using a wide range of fraction representations, which is necessary for developing fraction understanding (Kong 2008). 


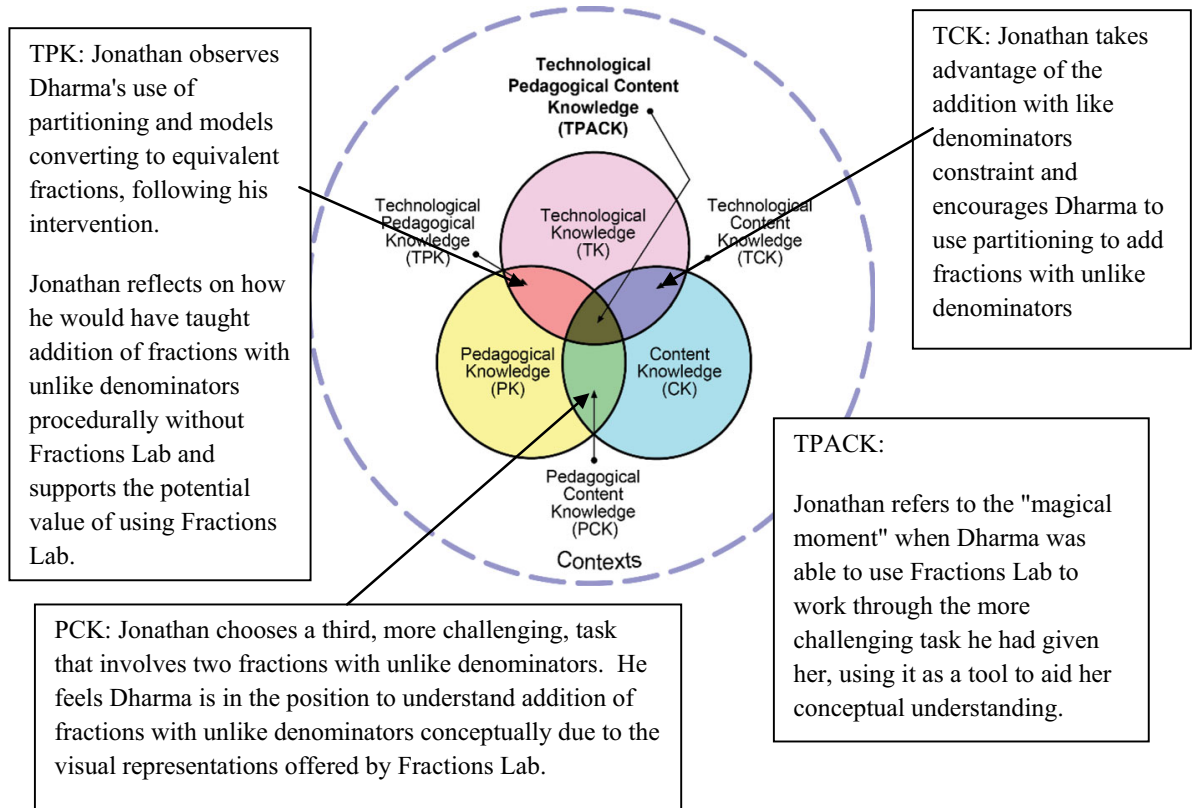

Fig. 4 The TPACK framework. Reproduced by permission of the publisher $\left({ }^{\odot} 2012\right.$ by tpack.org) and annotated with three exemplary instances of Jonathan's actions and reflections that lie in the intersection of the three forms of knowledge (content, pedagogy, technology) and the overall TPACK intersection

\section{Teachers' technological content knowledge}

Fractions Lab was designed with affordances and constraints to encourage children's conceptual understanding of fractions, but within the workshops we were interested in how the resource could shape the teachers' beliefs (Remillard et al. 2008) as they became codesigners in the next iterations. The teachers reported positively upon the affordances for children's understanding, such as the adding tool, equivalence tool, being able to make fractions, partitioning and its link with equivalence, and being able to "cut" parts and use them in addition or subtraction. These take advantage of the technology, enabling children and teachers to manipulate fractions in different ways than say on paper, supporting conceptual understanding through multiple viewpoints.

Although the affordances were designed with children's conceptual development in mind, we can see from the comments of the teachers how the affordances also challenged their thinking and consequently encouraged them to reflect upon their current approaches towards teaching fractions. For example, the partitioning tool enabled teachers to think about equivalent fractions using a mental model: "I'd never thought about splitting a rectangle up like that, you know, partitioning it so that you can see equivalent fractions so clearly. I've never made the connection myself before". The teachers also appeared to appreciate the constraint of Fractions Lab only allowing addition of fractions with like denominators; e.g. one teacher wrote that their pedagogy was challenged "To consider how methods such as adding fractions (where children would normally be expected to manipulate numbers) would be represented by pictures". 
In Phase 3 we saw how the process of design-in-use changed Jonathan's practice (Remillard et al. 2008). He went beyond appropriating the resource and quickly identified tasks to support a child who had not previously added fractions with unlike denominators. Specifically, in relation to Drijvers et al.'s (2010) elements of instrumental orchestration, he undertook didactical configuration by selecting the students, their groupings and Fractions Lab as the artefact involved; and exploited this configuration for the benefit of the students to learn how to add fractions with unlike denominators. Furthermore, he used Fractions Lab by selecting tasks on the fly to support the students, taking ad hoc decisions while teaching (didactical performance). Jonathan reflected on Dharma's learning and identified how he would have reverted to teaching procedurally had he not had access to Fractions Lab with the constraint embedded that allowed a conceptual approach to be followed.

\section{Teachers' technological pedagogical knowledge}

Despite the cohort comprising primary mathematics specialist teachers, 20 of the 21 teachers $(95 \%)$ who responded to this question felt that Fractions Lab challenged their own understanding of fractions to at least some extent. We therefore think that there is greater potential in introducing Fractions Lab to generalist primary teachers. Indeed, a high proportion of the MaSTs would recommend Fractions Lab to colleagues, "[Fractions Lab] will give other staff good visuals to use with their class to demonstrate fractions"; "A simple way to introduce fractions for a colleague who is unsure"; "This needs to be rolled all the way through school so that children learn more through exploration and see different representations". This response reflects the quality of the initial bootstrapping process undertaken that identified issues in fractions learning and teaching.

\section{Bringing it all together: teachers' technological pedagogical content knowledge}

During the workshops we were able to identify the three primary forms of knowledge: pedagogical, content and technological within Phase 1 or Phase 2. In Phases 3 and 4 we could see how Jonathan brought together the working environment, resource system, activity format and curriculum script (Ruthven 2009). Jonathan's class-based intervention and his reflection during Phase 4 provide an insight into the potential of using Fractions Lab in a design-based workshop and follow-up style, following the four phases of cooperative inquiry. One critical incident for us was the moment when Dharma was able to add $3 / 7$ and 1/3 using Fractions Lab with little input from Jonathan-in Jonathan's words "it was a magical moment". Jonathan recognised the positive impact of Fractions Lab on Dharma's conceptual understanding, and his teaching approach seems to be influenced by his newly acquired technological pedagogical content knowledge, particularly an appreciation of the potential of Fractions Lab as exploratory environment to support conceptual, rather than only procedural, learning.

\section{Conclusion}

Although a transformation of the virtual manipulative, Fractions Lab, occurred during our study, this article focuses on the role of the resource that was iteratively designed within an existing community of practice, to shape teachers' beliefs and practices. We were 
interested in how co-designing Fractions Lab enhanced teachers' technological, pedagogical and content knowledge.

While we appreciate that meaningful learning is a slow and uncertain process for teachers, just as it is for students (Borko 2004), the findings from our approach show that, even through a short design workshop, a resource primarily designed for children has the potential to challenge the assumptions of even experienced teachers when it is shared as an artefact on which they are asked to co-design and subsequently interact with, undertake tasks and design their own with the view of using them in subsequent phases of a cooperative inquiry process.

The process of becoming co-designers of Fractions Lab itself (from which the project has benefitted directly) allowed the workshop participants to engage deeply with Fractions Lab and its affordances. The data presented here show that the teachers' thinking about fractions was challenged because of some of the design decisions taken in the earlier bootstrapping process for Iteration 1 of Fractions Lab. In addition, the teachers taking part in our workshops considered how they might use Fractions Lab in their own classroom and they were in general agreement that they could use it in staff development to support their colleagues' pedagogical content knowledge related to fractions. These findings support our view that such opportunities can act as further professional development. In particular, apart from appreciating the potential of multiple representations, they seemed to appreciate the pedagogical assumptions behind the design principles of the virtual manipulative. The idea that as a virtual manipulative, Fraction Lab enables very different tasks for pupils and expects a different interaction than those on paper-and-pencil or most of the current procedural educational software (such as intelligent tutoring systems), was new to most of the participants.

While we are mindful that the workshops were short and that there might be a difference between well-meaning teachers' claims and the reality of using Fractions Lab in class, Jonathan's engagement during Phases 3 and 4 provides evidence for the potential longerterm impact of this current round of workshops and developing the process of design-inuse (Pepin et al. 2013) with the teachers. Facilitating in situ experiences with the resource can provide the "discrete intentional events" that Cobb et al. (2013) refer to and therefore support directly teachers' professional development by shaping their beliefs and practices (Remillard et al. 2008).

There are numerous projects (publicly and privately funded) that are designing educational technology, and they often appreciate the need and benefits of involving teachers (and students) in the design process. Only few, however, are looking at the potential of the participation process as a means of professional development activity - a view shared by Bossen et al. (2010), Drijvers et al. (2013) and Pepin et al. (2013). Our article adds to this emerging body of research by identifying two key aspects for successful PD through the co-design of virtual resources in communities of practice. We contribute to the existing literature by considering these aspects that were present implicitly within our method and offer tentative suggestions for others designing virtual resources to enhance teachers' professional development in communities of practice.

Aspect 1: the first iteration, designed by mathematics educationalists with input from target students as informants, used a principled approach that included a robust appreciation of (a) the use of a range of representations to learn and teach fractions (Hansen et al. 2014) and (b) the affordances and constraints of the technology (Hansen et al. 2013). This careful forethought was pivotal to the teachers' own practices and beliefs being challenged.

Aspect 2: in this instance we worked within an existing community of teachers, inviting them to be involved as co-designers in a cooperative inquiry approach to improving the virtual manipulative. The teachers, enrolled on a Mathematics Specialist Teacher course 
with a remit for improving mathematics education, were all highly motivated to be involved and were enthusiastic about the role the virtual manipulative could have on their own teaching. Crucially, because of their specialist teacher role in schools, they could also see the impact the virtual manipulative could have on their colleagues. While we see a place for setting up a new community of practice to undertake similar professional development opportunities, we were able to "hit the ground running" within a very short time period because we had tapped into this existing group of teachers.

There are several limitations to our study. The workshops were short, and while there was still a positive impact on the teachers' self-reported technological, pedagogical and content knowledge (which was later observed in their classrooms), we feel more time to familiarise themselves with the virtual manipulative and be engaged as co-designers over a longer period may have provided a more-consolidated start for some of the teachers for later phases in the study, particularly in relation to the exploratory design of Fractions Lab. Even though the teachers were involved with one learning technology, we are confident that they could see the potential value of similar learning technologies in mathematics education. Moreover, Fractions Lab and the cooperative design approach encouraged teachers' creativity in enhancing a learning technology, adapting it to their everyday classroom practices and making it "current".

In the later phases, the cooperative inquiry was undertaken between the teachers in their classrooms and the academic researchers visiting. This is time-consuming and could not be achieved at scale. Tapping into the existing community of practice further in order to encourage peer support may have been advantageous.

Further research is required to look at the long-term impact that initiatives such as this have on professional development. However, this article's contribution is to add to the existing professional development literature by making a case for PD opportunities that create the time and space to design and trial iterations of virtual manipulatives, making a positive impact on teachers' practice. We are inspired by Jonathan, and we saw him taking advantage of Fractions Lab's affordances and constraints in order to understand and further his students' knowledge and conceptual understanding of fraction addition.

We plan to extend our research by setting up a new community of practice of nonmathematics specialists from the very beginning of the design of a new virtual resource that will be used on a larger scale and involve the teachers over a longer period as codesigners. The setting up of a new community of practice will be more challenging, but we will embed the two aspects we identified in this research by continuing to work with highly motivated teachers who perceive themselves as agents of change (aspect 2) and work collaboratively to gather design requirements about the content area and the technological affordances and constraints available to us (aspect 1).

Acknowledgments The work described here has received funding by the EU in FP7 in the iTalk2Learn project (318051). Thanks to all our iTalk2Learn colleagues and particularly Testaluna s.r.l. for their support and ideas and implementing Fractions Lab. Thanks to Dr. Mary McAteer from Edge Hill University who facilitated our working with the Mathematics Specialist Teachers (MaSTs) on their courses and the MaSTs who volunteered to be involved in the research. Special thanks to Jonathan Leeming, who allowed us to publish his case study in the article.

Open Access This article is distributed under the terms of the Creative Commons Attribution 4.0 International License (http://creativecommons.org/licenses/by/4.0/), which permits unrestricted use, distribution, and reproduction in any medium, provided you give appropriate credit to the original author(s) and the source, provide a link to the Creative Commons license, and indicate if changes were made. 


\section{References}

Alajmi, A. H. (2012). How do elementary textbooks address fractions? A review of mathematics textbooks in the USA, Japan, and Kuwait. Educational Studies in Mathematics, 79, 239-261.

Baturo, A. R. (2004). Empowering Andrea to help year-5 students construct fraction understanding. In M. J. Hoines \& A. Fuglestad (Eds.), Proceedings of the 28th PME Conference (Vol. 2, pp. 95-102). Bergen.

BERA. (2011). Ethical Guidelines for Educational Research. London: British Educational Research Association. http://www.bera.ac.uk/wp-content/uploads/2014/02/BERA-Ethical-Guidelines-2011.pdf. Accessed June 2, 2014.

Borko, H. (2004). Professional development and teacher learning: Mapping the terrain. Educational Researcher, 33(3), 3-15.

Bossen, C., Dindler, C., \& Iversen, O. S. (2010). User gains and PD aims: Assessment from a participatory design project. In Proceedings of the 11th Biennial Participatory Design Conference (PDC '10) (pp. 141-150). ACM, New York, NY, USA.

Bowers, J., \& Stephens, B. (2011). Using technology to explore mathematical relationships: A framework for orienting mathematics courses for prospective teachers. Journal of Mathematics Teacher Education, 14, 285-304.

Chan, W. H., Leu, Y. C., \& Chen, C. M. (2007). Exploring group-wise conceptual deficiencies of fractions for fifth and sixth graders in Taiwan. Journal of Experimental Education, 76, 26-57.

Charalambous, C., Delaney, S., Hsu, H.-Y., \& Mesa, V. (2010). A comparative analysis of the addition and subtraction of fractions in textbooks from three countries. Mathematical Thinking and Learning, 12(2), $117-151$.

Clarke, D. M., \& Roche, A. (2009). Students' fraction comparison strategies as a window into robust understanding and possible pointers for instruction. Educational Studies in Mathematics, 72, 127-138.

Cobb, P., Confrey, I., diSessa, A., Lehrer, R., \& Schauble, L. (2003). Design experiments in educational research. Educational Researcher, 32(4), 9-13.

Cobb, P., Jackson, K., Smith, T. M., Sorum, M., \& Henrick, E. (2013). Design research with educational systems: Investigating and supporting improvements in the quality of mathematics teaching and learning at scale. In J. B. Fishman \& W. R. Penuel (Eds.), The National Society for the Study of Education yearbook 2013 (Vol. 112, p. 2). New York, NY: Teachers College Record.

Cohen, D. K., \& Hill, H. C. (2000). Instructional policy and classroom performance: The mathematics reform in California. Teachers College Record (Vol. 102, pp. 294-343). http://www-personal.umich. edu/ dkcohen/cohen_hill_2000_TCR.pdf. Accessed December 29, 2013.

Cooper, S. M., Wilkerson, T. L., Montgomery, M., Mechell, S., Arterbury, K., \& Moore, S. (2012) Developing a theoretical framework for examining student understanding of fractional concepts: An historical accounting. Forum on Public Policy Online, 2012(1).

Cox, S., \& Graham, C. R. (2009). Diagramming TPACK in practice: using an elaborated model of the TPACK framework to analyze and depict teacher knowledge. TechTrends, 53(5), 60-69.

Cramer, K. A., Post, T. R., \& del Mas, R. C. (2002). Initial fraction learning by fourth- and fifth-grade students: A comparison of the effects of using commercial curricula with the effects of using the rational number project curriculum. Journal for Research in Mathematics Education, 3(2), 111-144.

DfEE. (1999). The national numeracy strategy framework for teaching mathematics from reception to year 6. London: Department for Education and Employment.

DfES. (2003). E-learning strategy. London: Department for Education and Skills.

DfES. (2006). Primary framework for literacy and mathematics. London: Department for Education and Skills.

Drijvers, P., Doorman, M., Boon, P., Reed, H., \& Gravemeijer, K. (2010). The teacher and the tool: Instrumental orchestrations in the technology-rich mathematics classroom. Educational Studies in Mathematics, 75(2), 213-234.

Drijvers, P., Tacoma, S., Besamusca, A., Doorman, M., \& Boon, P. (2013). Digital resources inviting changes in mid-adopting teachers' practices and orchestrations. ZDM, 45, 987-1001.

Druin, A. (1999). Cooperative inquiry: developing new technologies for children with children. Proceedings of the SIGCHI conference on human factors in computing systems (CHI '99) (pp. 592-599). New York, NY, USA: ACM.

Druin, A. (2002). The role of children in the design of new technology. Behaviour and Information Technology, 21(1), 1-25.

Duval, R. (2006). A cognitive analysis of problems of comprehension in learning of mathematics. Educational Studies in Mathematics, 61, 103-131. 
Fishman, B. J., Penuel, W. R., \& Yamaguchi, R. (2006). Fostering innovation implementation: Findings about supporting scale from GLOBE. In S. A. Barab, K. E. Hay, \& D. T. Hickey (Eds.), Proceedings of the 7th international conference of the learning sciences (Vol. 1, pp. 168-174). Mahwah, NJ: Erlbaum.

Garet, M. S., Porter, A. C., Desimone, L., Birman, B. F., \& Yoon, K. S. (2001). What makes professional development effective? Results from a national sample of teachers. American Educational Research Journal, 38(4), 915-945.

Goos, M., \& Bennison, A. (2008). Surveying the technology landscape: Teachers' use of technology in secondary mathematics classrooms. Mathematics Education Research Journal, 20(3), 102-130.

Graham, C. R. (2011). Theoretical considerations for understanding technological pedagogical content knowledge (TPACK). Computers \& Education, 57, 1953-1960.

Gravemeijer, K., \& van Eerde, D. (2009). Design research as a means for building a knowledge vase for teachers and teaching in mathematics education. The Elementary School Journal, 109(5), 510-524.

Gueudet, G., Pepin, B., \& Trouche, L. (2013). Collaborative work with resources and teacher professional development. ZDM, The International Journal on Mathematics Education, 45, 1003-1016.

Hansen, A., Mavrikis, M., Holmes, H., Grawemeyer, B., Mazziotti, C., Mubeen, J., \& Koshkarbayeva, A. (2014). Report on learning tasks and cognitive models. Talk, tutor, explore, learn: Intelligent tutoring and exploration for robust learning. http://www.italk2learn.eu/deliverables-and-publications/deliverables/. Accessed June 9, 2015.

Hansen, A., Mavrikis, M., \& Orvieto, I. (2013). Requirements and technical state-of-the-art on intuitive interaction interfaces for robust learning. Talk, tutor, explore, learn: Intelligent tutoring and exploration for robust learning. http://www.italk2learn.eu/wp-content/uploads/2014/09/D3.2.pdf. Accessed June 9, 2015.

Henrik, E., Cobb, P., \& Jackson, K. (2014). Educational design research to support large-scale instructional improvement. In A. Bikner-Ahsbahs, C. Knipping, \& N. Presmeg (Eds.), Approaches to qualitative research in mathematics education: Examples of methodology and methods (pp. 497-531). New York: Springer.

Heron, J. (1996). Cooperative inquiry: Research into the human condition. London: Sage.

Heron, J., \& Reason, P. (2001). The practice of co-operative inquiry: Research with rather than on people. In P. Reason \& H. Bradbury (Eds.), Handbook of action research: Participative inquiry and practice (pp. 179-188). London: Sage.

Jaworski, B. (2001). Developing mathematics teaching: Teachers, teacher-educators, and researchers as colearners. In F.-L. Lin \& T. J. Cooney (Eds.), Making sense of mathematics teacher education (pp. 295-320). Dordrecht, The Netherlands: Kluwer.

Jaworski, B. (2003). Research practice into/influencing mathematics teaching and learning development: Towards a theoretical framework based on co-learning partnerships. Educational Studies in Mathematics., 54(2-3), 249-282.

Kafai, Y. (2003). Children designing software for children: What can we learn? Small users-Big ideas: Proceedings of interaction design and children 2003 conference, New York: ACM Press (pp. 11, 12).

Koehler, M. J., \& Mishra, P. (2009). What is technological pedagogical content knowledge? Contemporary Issues in Technology and Teacher Education, 9(1), 60-70.

Kong, S. C. (2008). The development of a cognitive tool for teaching and learning fractions in the mathematics classroom: A design-based study. Computers \& Education, 51(2), 886-899.

Lamon, S. J. (2012). Teaching fractions and ratio for understanding: essential content knowledge and instructional strategies for teachers (3rd ed.). New York: Routledge.

Lieberman, A. (1995). Practices that support teacher development: Transforming conceptions of professional learning. Phi Delta Kappan, 76-81, 591-596.

Mishra, P., \& Koehler, M. J. (2006). Technological pedagogical content knowledge: A new framework for teacher knowledge. Teachers College Record, 108(6), 1017-1054.

Olive, J., \& Lobato, J. (2008). The learning of rational number concepts using technology. In M. K. Heid \& G. W. Blume (Eds.), Research on technology in the teaching and learning of mathematics: Research syntheses (Vol. 1, pp. 1-54). Greenwich, CT: Information Age Publishing, Inc.

Pantziara, M., \& Philippou, G. (2012). Levels of students' “conception” of fractions. Educational Studies in Mathematics, 79, 61-83.

Penuel, W. E., Roschelle, J., \& Shechtman, N. (2007). Designing formative assessment software with teachers: An analysis of the co-design process. Research and Practice in Technology Enhanced Learning, 2(1), 51-74.

Pepin, B., Gueudet, G., \& Trouche, L. (2013). Re-sourcing teachers' work and interactions: a collective perspective on resources, their use and transformation. ZDM, The International Journal on Mathematics Education, 45(7), 929-943.

Plomp, T., \& Nieveen, N. (Eds.). (2009). An introduction to educational design research. Enschede: SLONetherlands Institute for Curriculum Development. 
Reason, P. (1995). Participation in human inquiry. London: Sage.

Reimann, P. (2013). Design-based research-Designing as research. In R. Luckin, S. Puntambekar, P. Goodyear, B. Grabowski, J. Underwood, \& N. Winters (Eds.), Handbook of design in educational technology (pp. 44-52). New York: Routledge.

Remillard, J. (2013). Examining resources and re-sourcing as insights into teaching. ZDM: The International Journal on Mathematics Education, 45(7), 925-927.

Remillard, J., Herbel-Eisenmann, B. A., \& Lloyd, G. M. (Eds.). (2008). Mathematics teachers at work: Connecting curriculum materials and classroom instruction. New York: Routledge.

Ruthven, K. (2009). Towards a naturalistic conceptualisation of technology integration in classroom practice: The example of school mathematics. Education \& Didactique, 3(1), 131-159.

Scaife, M., Rogers, Y., Aldrich, F., \& Davies, M. (1997). Designing for or designing with? Informant design for interactive learning environments. In CHI'97: Proceedings of Human Factors in Computing Systems. ACM: New York (pp. 343-350).

Siegler, R. S., Duncan, G. J., Davis-Kean, P. E., Duckworth, K., Claessens, A., Engel, M., et al. (2012). Early predictors of high school mathematics achievement. Psychological Science, 23(7), 691-697.

Silver, E. A. (1983). Probing young adults' thinking about rational numbers. Focus on learning problems in mathematics, 5, 105-117.

Stephan, M. L. (2014). Conducting classroom design research with teachers. ZDM Mathematics Education, 47(6), 1-13.

Timperley, H., Wilson, A., Barrar, H., \& Fung, I. (2007). Teacher professional learning and development: Best evidence synthesis iteration. Wellington, New Zealand: Ministry of Education.

Trigueros, M., \& Lozano, D. (2012). Teachers teaching mathematics with Enciclomedia. In G. Gueudet, B. Pepin, \& L. Trouche (Eds.), From text to 'lived' resources: Mathematics curriculum materials and teacher development (pp. 247-264). New York: Springer.

Trouche, L. (2004). Managing complexity of human/machine interactions in computerized learning environments: Guiding students' command process through instrumental orchestrations. International Journal of Computers for Mathematical Learning, 9, 281-307.

Voogt, J., Fisser, P., Pareja Roblin, N., Tondeur, J., \& Van Braak, J. (2013). Technological pedagogical content knowledge-A review of the literature. Journal of Computer Assisted Learning, 29(2), $109-121$.

Walker, M., Straw, S., Jeffes, J., Sainsbury, M., Clarke, C., \& Thom, G. (2013). Evaluation of the Mathematics Specialist Teacher (MaST) programme: Research report. London: National Foundation for Educational Research \& SQW. http://www.nfer.ac.uk/publications/PMSZ01/PMSZ01.pdf. Accessed April 22, 2014.

Williams, P. (2008). Independent review of mathematics teaching in early years settings and primary schools: Final report. London: Department for Children, Schools and Families.

Wilson, S. M., \& Berne, J. (1999). Teacher learning and the acquisition of professional knowledge: An examination of research on contemporary professional development. In A. Iran-Nejad \& P. D. Pearson (Eds.), Review of research in education (Vol. 24, pp. 173-209). Washington, DC: American Educational Research Association. 